\title{
Habitat effects on population connectivity in a coastal seascape
}

\author{
Lauren A. Rogers ${ }^{1, *}$, Esben Moland Olsen ${ }^{1,2,3}$, Halvor Knutsen ${ }^{1,2,3}$, \\ Nils Chr. Stenseth ${ }^{1,2,3}$ \\ ${ }^{1}$ Centre for Ecological and Evolutionary Synthesis (CEES), Department of Biosciences, University of Oslo, PO Box 1066 , \\ Blindern, 0316 Oslo, Norway \\ ${ }^{2}$ Institute of Marine Research, Flødevigen, 4817 His, Norway \\ ${ }^{3}$ Centre for Coastal Research (CCR), Department of Natural Sciences, University of Agder, 4604 Kristiansand, Norway
}

\begin{abstract}
Knowing how population connectivity varies across heterogeneous habitats can provide insight into the mechanisms underlying population structuring, and ultimately help to inform conservation and management actions. We studied whether the spatial extent of connectivity in coastal Atlantic cod Gadus morhua varied with coastal topography, hypothesizing that connectivity during all life stages would be greater among open, exposed habitats compared to sheltered, fjord-like habitats. We tested this hypothesis using (1) an extensive mark-recapture data set to analyze movements of age 1+ cod along a gradient from inshore (sheltered) to offshore (exposed) habitats, and (2) an analysis of demographic dependence (recruitment synchrony) among exposed versus sheltered areas using a 93 yr spatially explicit time series of juvenile (age-0) abundance. We found that habitat did have a significant effect on both the scale of recruitment synchrony and movement distances, both of which were greater in exposed regions relative to sheltered. However, even in open habitats, tagged cod were highly sedentary, and connectivity among regions due to movement of age 1+ individuals was exceptionally low. Thus, despite likely differences among habitats in dispersal of egg and larval stages, older cod were highly site-attached regardless of habitat. These results highlight how physical habitat interacts with behavior to determine the scale of population structuring in marine fishes.
\end{abstract}

KEY WORDS: Migration · Population structure · Skagerrak coast · Southern Norway · Synchrony · Connectivity $\cdot$ Dispersal

Resale or republication not permitted without written consent of the publisher

\section{INTRODUCTION}

Population spatial structure emerges from a set of processes determining the connectivity and isolation of population subunits over space and time (reviewed by Ciannelli et al. 2013). Dispersal of individuals over space will tend to erode genetic structure and synchronize population dynamics, whereas natal homing and small home-ranges will promote genetic differentiation, local adaptation, and demographic independence among subpopulations. A wealth of terrestrial studies have shown that the spatial scale of these processes is often linked to landscape features which may, for instance, facilitate movement or determine the direction of dispersal (Manel et al. 2003, Baguette \& Van Dyke 2007). As in terrestrial landscapes, marine seascapes are heterogeneous environments, and the spatial scale of connectivity processes may vary depending on seascape features (e.g. Banks et al. 2007). Therefore, characterizing patterns of connectivity, and how they vary across a seascape, can provide important information for understanding population spatial structure in marine environments and the mechanisms that underlie it.

Marine fish populations were long thought to be demographically open and genetically homogeneous 
over broad expanses (Hjort \& Dahl 1900, reviewed in Hauser \& Carvalho 2008). This was largely due to the wide dispersal potential of pelagic eggs and larvae in oceanic currents and frequently-observed migrations in older fish. However, genetic and demographic structure is increasingly being documented at relatively fine spatial scales (Conover et al. 2006, Jorde et al. 2007, Hauser \& Carvalho 2008, Knutsen et al. 2011). The mechanisms used to explain such population structure in marine environments include the retention of eggs and larvae in currents or eddies (Sponaugle et al. 2002, Morgan et al. 2009, Ciannelli et al. 2010), high mortality of dispersing individuals (Koehn et al. 1980), and the homing of larval and mature fish to natal habitats (Jones et al. 1999, Thorrold et al. 2001). While the scale of larval dispersal has often been the focus of studies on marine population connectivity, adult behavior can also be a crucial factor (Frisk et al. 2014). It is therefore the combination of processes acting on early life stages as well as the behavior of older individuals which ultimately determines the spatial scale of population structuring and the degree of connectivity between sub-areas or regions.

Coastal ecosystems are dynamic and heterogeneous environments, often characterized by complex topography and currents. Such physical habitat features may result in spatial differences in larval or adult dispersal distances, and subsequent differences in the scale of population structuring. Recent studies of Atlantic cod Gadus morhua along the Norwegian Skagerrak coast suggest that coastal topography may be linked to population spatial structure. Genetic studies of coastal cod sampled in small fjords have documented population structure at a scale down to approximately $30 \mathrm{~km}$ (Knutsen et al. 2003, Jorde et al. 2007), where the pattern most likely arises from individuals sampled in sheltered locations far inside the fjords (Knutsen et al. 2011). Differences in coastal cod life-history traits have been observed at a similar spatial scale, indicative of local adaptations (Olsen et al. 2008). In contrast, genetic structure is less evident in more open continental shelf habitats (i.e. outside fjords) influenced by a strong coastal current (Knutsen et al. 2004, 2011). Together, these studies suggest that the spatial scale of population structuring and connectivity may vary among open and sheltered coastal areas.

While genetic tools can provide valuable information regarding population spatial structure, genetic signals become eroded at even very low levels of connectivity, equivalent to the exchange of only a few individuals per generation (Hauser \& Carvalho
2008). Ecologically relevant structure may thus go undetected using only genetic tools, necessitating alternative approaches to study connectivity and population spatial structure. For instance, tracking of individuals can indicate the degree of connectivity among sub-areas, common garden studies can detect local adaptations which may go unnoticed by genetic tools (Hutchings et al. 2007), and demographic analysis can indicate whether (sub-) populations display demographic independence, which is generally considered to occur when fewer than $10 \%$ of individuals are exchanged between sub-areas (Hastings 1993). However, such approaches are often challenging in marine environments due to the difficulty of observing individual organisms and the lack of demographic data on appropriate spatial or temporal scales.

Here, we analyze the movements of individuals together with spatial patterns in recruitment dynamics to draw inferences about connectivity along the Skagerrak coast during multiple life stages of Atlantic cod. We hypothesize that coastal topography plays an important role in determining the spatial scale of connectivity in coastal cod populations. We expect that populations inside fjords will be structured at a finer scale than those in outer coastal areas, and that this will be reflected in the recruitment dynamics and in the behavior of older life stages. We first analyze a $93 \mathrm{yr}$ time series of juvenile cod abundance sampled along $\sim 250 \mathrm{~km}$ of the coastline to compare the spatial scale of recruitment synchrony among open versus sheltered areas. We then compare these results to the spatial patterns of juvenile and adult movements using an extensive markrecapture study of cod tagged along a gradient from sheltered to open habitats in 3 separate regions of the Norwegian Skagerrak coast. This allows us to examine differences in movement strategies among cod found inside versus outside of fjords, as well as to detect connectivity to offshore areas such as the North Sea. Finally, we put these results in the context of recent population genetics findings to draw general conclusions about patterns of connectivity and scales of population structuring in complex coastal habitats.

\section{MATERIALS AND METHODS}

\section{Study area and species}

The Atlantic cod Gadus morhua is an ecologically important harvested species found in coastal and offshore shelf habitats in the North Atlantic. It is a highly 
Fig. 1. Study area. Locations of beach seine stations used in the Atlantic cod recruitment analysis are indicated by triangles and colored according to their degree of exposure to the open Skagerrak. Regions where tagging of individuals took place are indicated by (a) Lillesand, (b) Arendal, and (c) Risør

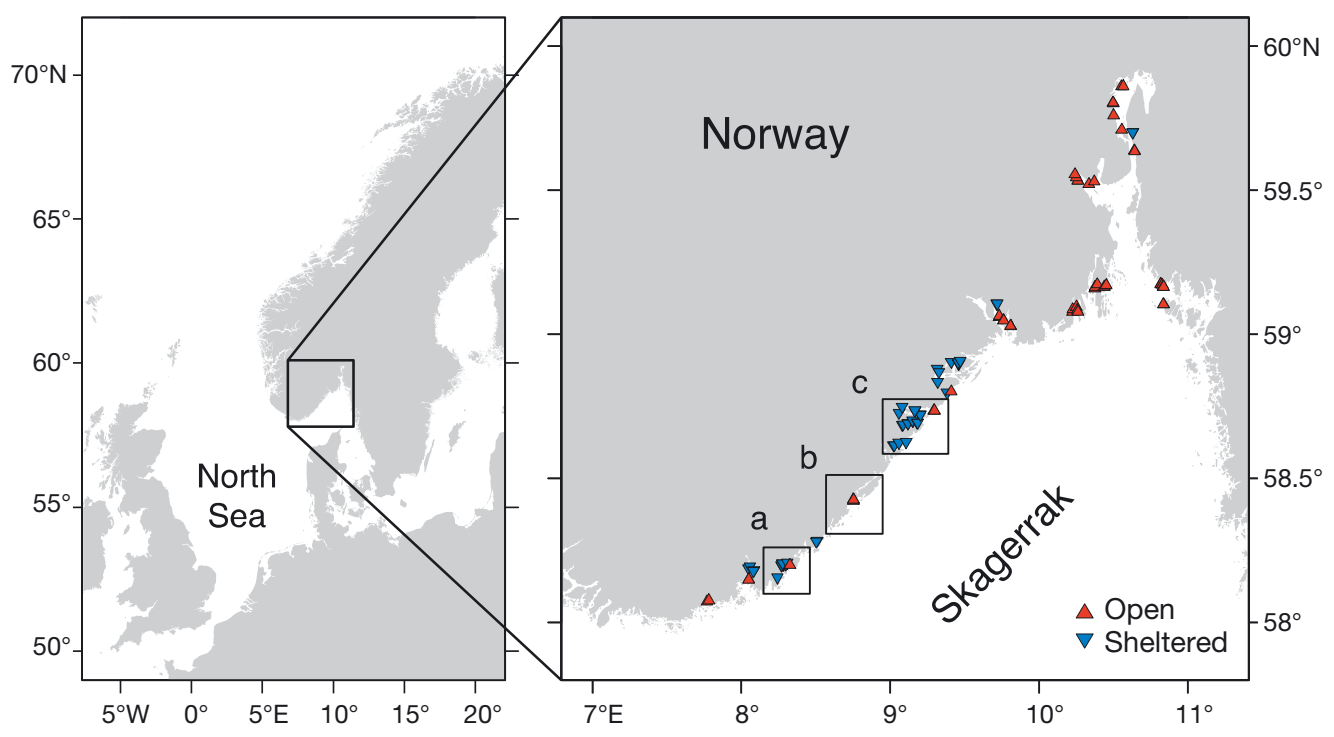

fecund batch-spawner with pelagic eggs and larvae (Kjesbu 1989). In the coastal Skagerrak (Fig. 1), the larvae metamorphose into juveniles and settle in nearshore nursery areas during May and June. Growth is about 10 to $15 \mathrm{~cm} \mathrm{yr}^{-1}$ and maturity sets in at an age of 2 to $4 \mathrm{yr}$ and a body length of 30 to $50 \mathrm{~cm}$ (Dannevig 1954, Olsen et al. 2008). Spawning has been documented in some fjords, particularly in sheltered areas away from the Norwegian Coastal Current (Knutsen et al. 2010), but comprehensive knowledge of spawning locations is lacking. Coastal cod in the Skagerrak experience considerable harvest pressure from both commercial and recreational fishers, and few individuals survive past age 5 (Julliard et al. 2001).

\section{Long-term beach seine survey}

Since 1919, an annual beach seine survey has been conducted to study variability in juvenile cod abundance on the Norwegian Skagerrak coast (see Stenseth et al. 1999 for a detailed description). The survey initially included 66 sampling stations between the southern tip of Norway and Kragerø, and since 1936 has extended north to Oslo Fjord and east to the Swedish border (Fig. 1). Stations are distributed from sheltered locations far inside fjords to exposed areas on the open Skagerrak coast. The survey is carried out in September to October of each year and primarily captures half-year old cod (hereafter referred to as 'age-0' or 'recruits'). The abundance of age-0 cod in autumn will reflect the reproductive output of spawners, the probability of larvae drifting to and settling at a particular site, and survival through the first summer.
Spatial scale of recruitment synchrony

Spatial coherence in age-0 variability could arise if juveniles come from a common pool of spawners, if eggs and larvae from multiple pools of spawners are mixed prior to settling in demersal habitats, or if exposure to common environmental conditions has spatially similar effects on spawning or early-life survival. To calculate the spatial coherence in the variability of age- 0 cod abundance, we calculated the Pearson's correlation coefficient in log-transformed age- 0 catches for each pair of stations. A constant of 1 was added to all catches to avoid taking the log of zero counts. Log-transformation has the effect of reducing the influence of extreme high catches on correlation coefficients. However, because catches were sometimes zero, often low (e.g. $<10$ ind.), and occasionally very high (max. catch = 934 ind.), we also calculated correlations assuming a bivariate Poisson log-normal distribution (Engen et al. 2008), which may be more appropriate for overdispersed count data (O'Hara \& Kotze 2010). We selected only those stations which were sampled at least $50 \%$ of the years since 1919 ( $\mathrm{n}=95)$, and correlations were only calculated for pairs of stations which overlapped in their temporal coverage by at least 20 yr.

We quantified the rate at which correlations in age0 abundance decreased with increasing geographic distance by fitting an exponential decay model:

$$
\rho(d)=\rho_{\mathrm{r}}+\rho_{0} \mathrm{e}^{-\left(\frac{d}{V}\right)}
$$

where $\rho(d)$ is the pairwise correlation at distance $d, \rho_{\mathrm{r}}$ is the asymptotic correlation, or background regional 
correlation in recruitment, and $\rho_{\mathrm{r}}+\rho_{0}$ is the estimated correlation at zero distance. The parameter $v$ describes the rate at which correlations decrease with distance, and is referred to as the e-folding scale (Bjørnstad et al. 1999). Specifically, $v$ estimates the distance at which the pairwise correlation between time series is reduced to $\sim 37 \%\left(\mathrm{e}^{-1}\right)$ of that at zero distance, relative to the background regional level of correlation. This model was modified from that of Myers et al. (1997) and Bjørnstad et al. (1999) by including an additional term $\left(\rho_{\mathrm{r}}\right)$ such that the correlation at maximum distance is not assumed to be zero.

To test our hypothesis that the spatial scale of recruitment synchrony would be greater for cod in open habitats outside fjords, we classified stations according to their degree of exposure to the open sea, and fit models separately to sheltered versus exposed stations in order to compare estimates of $v$. A second set of models were fit to first-differenced log-transformed data in order to remove long-term trends from the survey data. Models were fit using non-linear least squares in $\mathrm{R}$ ( $\mathrm{R}$ Development Core Team 2011), with pairwise correlations weighted by the number of overlapping years used to calculate each correlation. Bivariate Poisson log-normal distributions were estimated using the function 'bipoilogMLE' in the 'poilog' package in R. A cost-distance function, implemented using the 'gdistance' package in $\mathrm{R}$, was used to calculate the shortest distance over water between stations.

\section{Mark-recapture-recovery study}

From 2005 to 2010, a mark-recapture-recovery study was conducted along the southern part of the Norwegian Skagerrak coast. Cod were captured in fyke nets between April and June and individually marked with an external T-bar anchor tag (TBA-2, Hallprint). A total of 9518 individual cod were tagged and released. Tagged individuals ranged from 15 to $93 \mathrm{~cm}$ in total length (mean $=40 \mathrm{~cm}$ ), corresponding to ages 1 and older. All cod were captured in shallow water ( 1 to $5 \mathrm{~m}$ depth) and released at the exact point of capture immediately after being tagged and measured. Earlier studies have evaluated T-bar tagging mortality and tag loss in Atlantic cod, and found similar short-term mortalities between tagged and untagged cod (control group), while annual tag loss could be in the range of 10 to $20 \%$ (Brattey \& Cadigan 2004, Cadigan \& Brattey 2006). In our study, recaptures consisted of live recaptures by researchers and by local eel fishers who were paid to report and release cod caught in their fyke nets as bycatch, and dead recoveries which were reported by recreational and commercial fishers. To encourage the reporting of marked fish, tags were printed with a return address and reward (either 50 or 500 Norwegian kroner). When available, the date, location, and length at recapture were recorded. When exact latitude and longitude were unavailable, an approximate latitude and longitude were assigned based on the description of the area.

Tagging effort was focused in 3 sections of coastline with differing structure and bathymetry nearby the towns of Lillesand, Arendal, and Risør (Fig. 1). Within each region, tagging effort was well-distributed along a gradient from the innermost habitats of fjords to outer islands, which are exposed to the open sea (Fig. 2). Previous work has suggested that cod eggs are largely retained within fjords by inward-flowing currents and shallow sills, promoting the maintenance of local population structure (Ciannelli et al. 2010). The fjords near Lillesand and Risør have such sills, whereas Arendal does not and is more appropriately described as a bay, partially protected from the Skagerrak by coastal islands.

\section{Statistical modeling of movement patterns}

Generalized additive models (GAMs) were used to determine whether there were spatial patterns in movement distances, or whether there were other ecological factors associated with movement distances. For each region, the distance (calculated as the shortest distance over water) between tagging location and final recapture location was natural log-transformed and modeled as a bivariate smooth function of the latitude and longitude of tagging. Additional terms considered were the number of days between tagging and recapture (DaysBtw), the month of tagging (fMonthT) and of recapture (fMonthR), and the total length at tagging (Length). Thin plate regression splines were used for each term except month, which was modeled as a factor. Models were restricted to include only individuals with at least $30 \mathrm{~d}$ at liberty. Model selection proceeded by comparing the generalized cross validation (GCV) scores of competing models, with a lower GCV indicating lower prediction error and thus a stronger model. All GAMs were implemented in the 'mgcv' library in R (Wood 2006). 

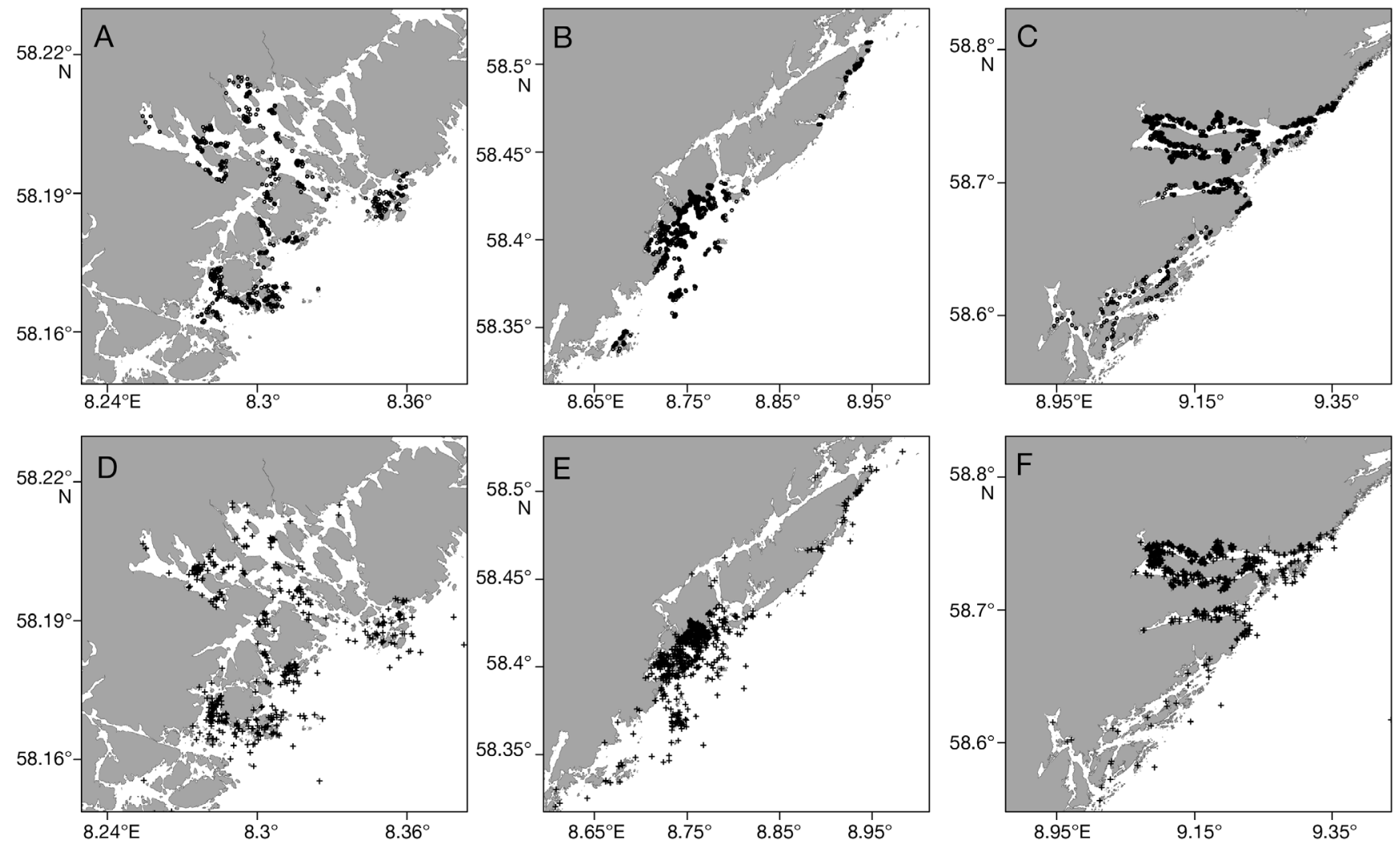

Fig. 2. (A-C) Tagging locations of Atlantic cod and (D-F) final recapture locations within the regions Lillesand (A,D), Arendal $(\mathrm{B}, \mathrm{E})$, and Risør $(\mathrm{C}, \mathrm{F})$

\section{RESULTS}

\section{Spatial scale of covariation in recruitment}

Temporal variation in the abundance of age- 0 cod was correlated among all regions of the Norwegian Skagerrak coast (Fig. 3). Correlations were highest among nearby stations, and declined with increasing distance. This decline occurred rapidly when comparing among stations inside fjords, with correlations remaining above background regional levels only for stations less than $\sim 25 \mathrm{~km}$ apart. This corresponds to roughly the scale of a single fjord. In contrast, stations on the outer coast showed a coarser spatial structuring, with elevated recruitment synchrony up to distances of approximately $75 \mathrm{~km}$. Accordingly, $v$ was estimated to be 3 times larger in exposed versus sheltered areas $(v=33.7$ and $11.6 \mathrm{~km}$, respectively, based on analysis of log-transformed count data). $\left(\rho_{0}+\rho_{\mathrm{r}}\right)$ and $\rho_{\mathrm{r}}$ were not significantly different between sheltered and exposed

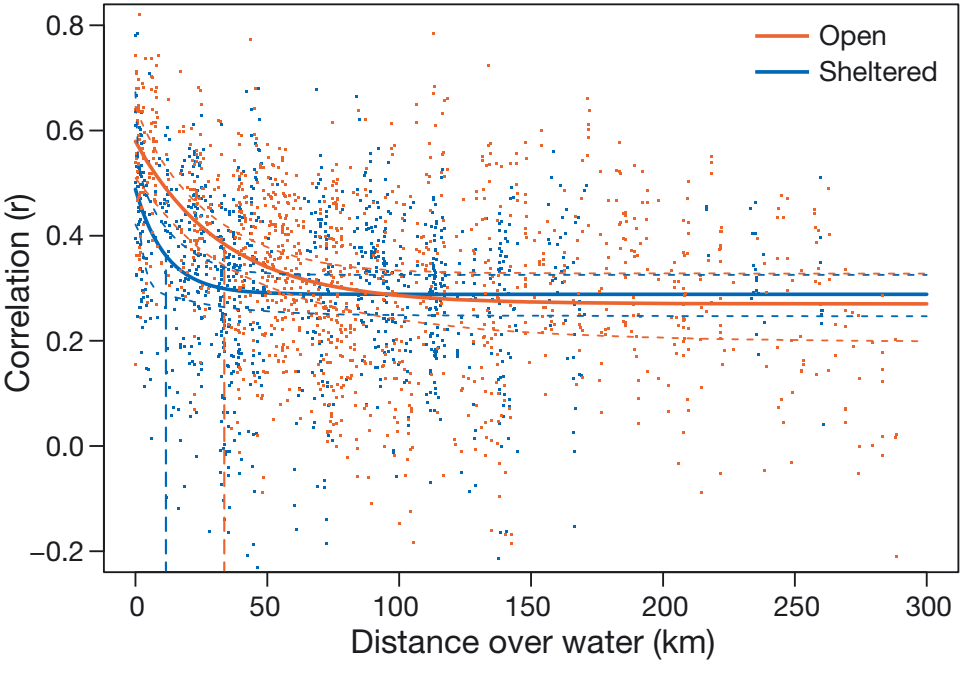

Fig. 3. Pairwise correlations among time-series of log(age-0 abundance) of Atlantic cod for 95 stations along the Norwegian Skagerrak coast. Solid lines show the fitted exponential decay model for stations in sheltered (dark blue) and open (light orange) areas, along with bootstrapped $95 \%$ confidence intervals (dashed lines). Vertical dashed lines indicate the e-folding scale $(\mathrm{V})$, estimated to be $11.6 \mathrm{~km}(95 \% \mathrm{CI}=$ 1.8-27.4) for stations in sheltered areas, and $33.7 \mathrm{~km} \mathrm{(95 \%} \mathrm{CI} \mathrm{=} \mathrm{20.3-}$ 57.9 ) for stations on the outer coast. Confidence intervals are based on 10000 bootstrap replicates (Bjørnstad et al. 1999) 
Table 1. Mark-recapture experiment on Atlantic cod carried out from 2005 to 2010 in 3 regions along the Norwegian Skagerrak coast. Final recapture locations are given for cod tagged in the 3 primary study regions. For recapture locations outside the study regions, SW indicates coastal areas to the southwest of Lillesand, and NE indicates coastal areas to the northeast of Risør. Offshore recaptures include those in the Skagerrak near Norway, Denmark and Sweden, and in the North Sea

\begin{tabular}{|c|c|c|c|c|c|c|c|c|c|c|}
\hline \multirow{3}{*}{$\begin{array}{l}\text { Tagging } \\
\text { region }\end{array}$} & \multirow{3}{*}{$\begin{array}{c}\text { No. } \\
\text { marked }\end{array}$} & \multirow{3}{*}{$\begin{array}{c}\text { No. } \\
\text { re- } \\
\text { captured }\end{array}$} & \multirow{3}{*}{$\begin{array}{c}\text { Median } \\
\text { distance } \\
(\mathrm{km})\end{array}$} & \multirow{3}{*}{$\begin{array}{c}\text { Moved } \\
>20 \mathrm{~km}\end{array}$} & \multicolumn{6}{|c|}{ Recapture location } \\
\hline & & & & & \multicolumn{3}{|c|}{ Within study regions } & \multicolumn{2}{|c|}{ Coastal Skagerrak } & \multirow[t]{2}{*}{ Offshore } \\
\hline & & & & & Lillesand & Arendal & Risør & SW & NE & \\
\hline Lillesand & 1663 & 646 & 0.26 & 13 & 631 & 4 & 0 & 4 & 1 & 6 \\
\hline Arendal & 3883 & 1309 & 0.38 & 36 & 1 & 1274 & 6 & 11 & 4 & 13 \\
\hline Risør & 3972 & 1347 & 0.37 & 20 & 0 & 9 & 1328 & 1 & 3 & 6 \\
\hline
\end{tabular}

stations. Analysis of first-differenced data gave nearly identical results $(v=36.9 \mathrm{~km}$ for exposed areas and $11.4 \mathrm{~km}$ for sheltered areas). Results from the bivariate Poisson log-normal model agreed with the analysis of log-transformed counts $(v=32.0 \mathrm{~km}$ for exposed areas and $10.8 \mathrm{~km}$ for sheltered areas).

\section{Movement patterns of age $1+\operatorname{cod}$}

Out of a total of 9518 fish that were tagged and released, $3302(35 \%)$ were recaptured at least once during the duration of the study (Table 1, Table S1 in the Supplement at www.int-res.com/articles/suppl/ m511p153_supp.pdf). Of these, 715 were recaptured multiple times. Only the final recapture occasion (dead or alive) was considered for subsequent analyses of movement patterns. The median number of days between tagging and final recapture was 115 (range: 2 to 1588). Final recaptures were primarily made by recreational $(45 \%)$ and professional $(42 \%)$ fishers, with a smaller proportion $(13 \%)$ made by researchers. Recaptures were well distributed throughout the 3 study regions, from the most sheltered areas to the outer coast and offshore (Fig. 2). The majority of recaptures occurred in summer, likely reflecting increased fishing effort during this time (especially by recreational fishers on holiday) but recaptures were reported during all months of the year (Fig. S1 in the Supplement).

The vast majority of individuals were recaptured in close proximity to their tagging location (Fig. 4B,C). Considering all recaptured individuals, $81 \%$ were caught within $1 \mathrm{~km}$ of where they were tagged and released. Of those at liberty for a minimum of $1 \mathrm{yr}$ $(\mathrm{n}=681), 71 \%$ were recaptured within $1 \mathrm{~km}$ of their
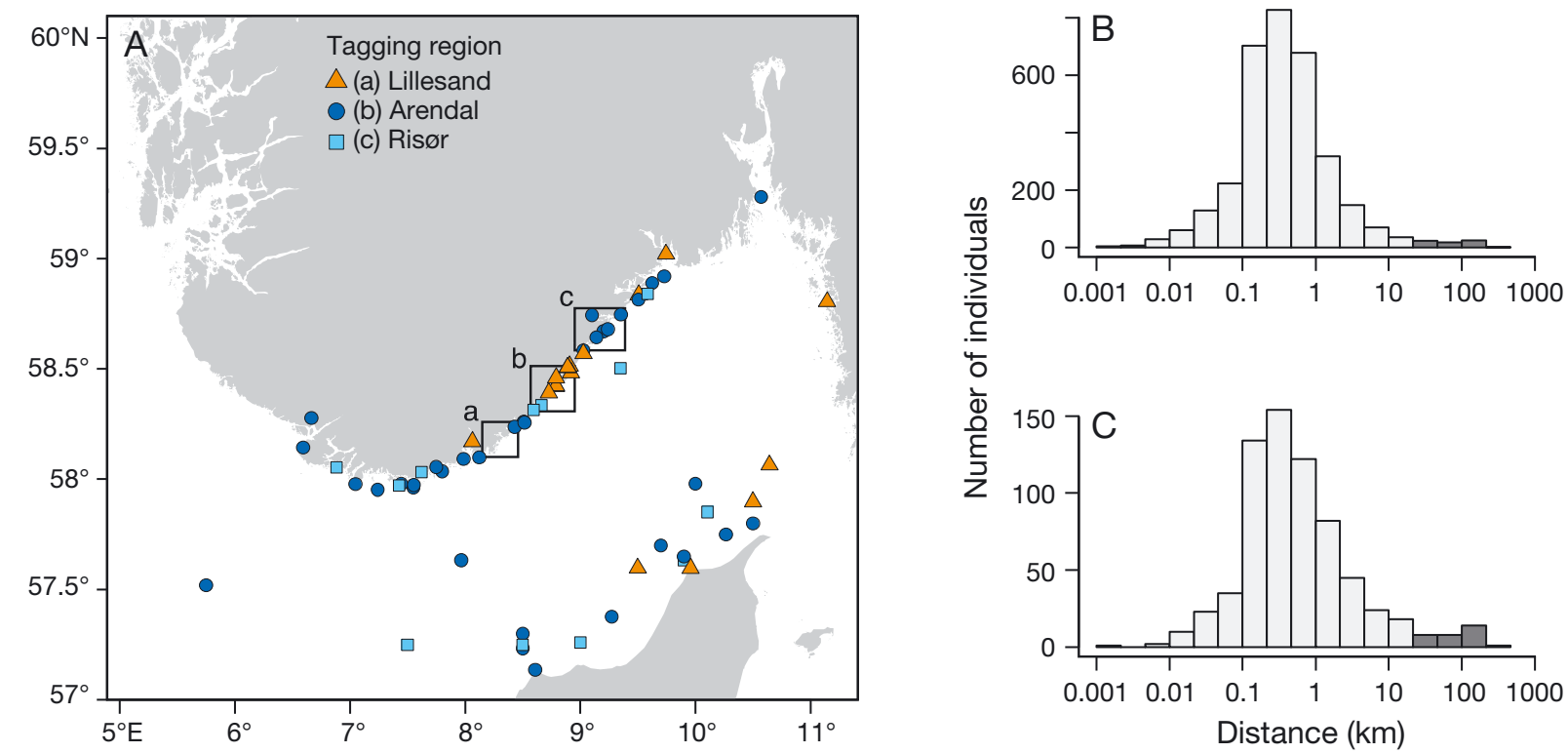

Fig. 4. (A) Recapture locations of long-distance dispersers (Atlantic cod recaptured $>20 \mathrm{~km}$ from tagging location). Symbols indicate the region where tagged. The distribution of distances between tagging and final recapture locations are shown for (B) all recaptured individuals and (C) individuals with at least 1 yr at liberty. Long-distance dispersers (dark bars) represented only $2 \%$ of all recaptures 
tagging location. Almost all (98\%) of the documented movements occurred within fjords or regions (Table 1). Forty-four individuals were captured elsewhere along the Skagerrak coast, and 25 were caught far offshore, either towards the Danish coast or in the North Sea proper (Table 1, Fig. 4A). Assuming a recapture rate of $35 \%$ and similar mortality rates between stationary and non-stationary fish, we estimate that approximately $2 \%$ of the cod present in the coastal Skagerrak region in April to June exhibited long-distance dispersal, defined as movements $>20 \mathrm{~km}$. This is an underestimate if the probability of a tagged fish being recaptured and reported was lower in regions outside the study area, or if mortality was higher among dispersing fish.

Within-region differences in movement patterns were indicated by GAMs. The best model of the distance between tagging and recapture locations for each region, according to GCV scores, included a bivariate smooth term for latitude/longitude where tagged, the month of recapture, and a smooth or linear term for the number of days between tagging and recapture (Table S2 in the Supplement). Length at tagging was also included as a linear term in the final models for Arendal and Risør, indicating a slight increase in log(distance) with larger body size (Fig. S2 in the Supplement). The final models explained between 13.1 and $22.3 \%$ of the variance in $\log$ (distance).

All 3 regions demonstrated clear spatial patterns in the distance between tagging and recapture locations, with the distance being generally greater for fish tagged in exposed areas rather than in more sheltered areas (Fig. 5). This gradient was clearest for the Lillesand region, with fish tagged in the inner parts of the fjord showing the shortest movement distances within any of the regions. The onshore/ offshore gradient was least clear in Arendal and the predicted movement distances were on average higher than in the other 2 regions, with cod tagged around some offshore islands showing the greatest movement distances. These spatial patterns did not change when fish recaptured less than 1 yr after tagging were excluded.

Fig. 5. For regions (A) Lillesand, (B) Arendal, and (C) Risør, colors show the fitted generalized additive model (GAM) prediction surface based on the latitude and longitude of the location of tagging Atlantic cod, indicating spatial patterns in the distance between tagging and recapture locations. Symbols indicate the tagging locations of fish recaptured at least 30 d later, with red stars indicating the fish which were recaptured $>20 \mathrm{~km}$ away. Predicted distances are given for median values of the other covariates (length $=470 \mathrm{~mm}$, days at liberty $=115$, month of recapture $=$ July)
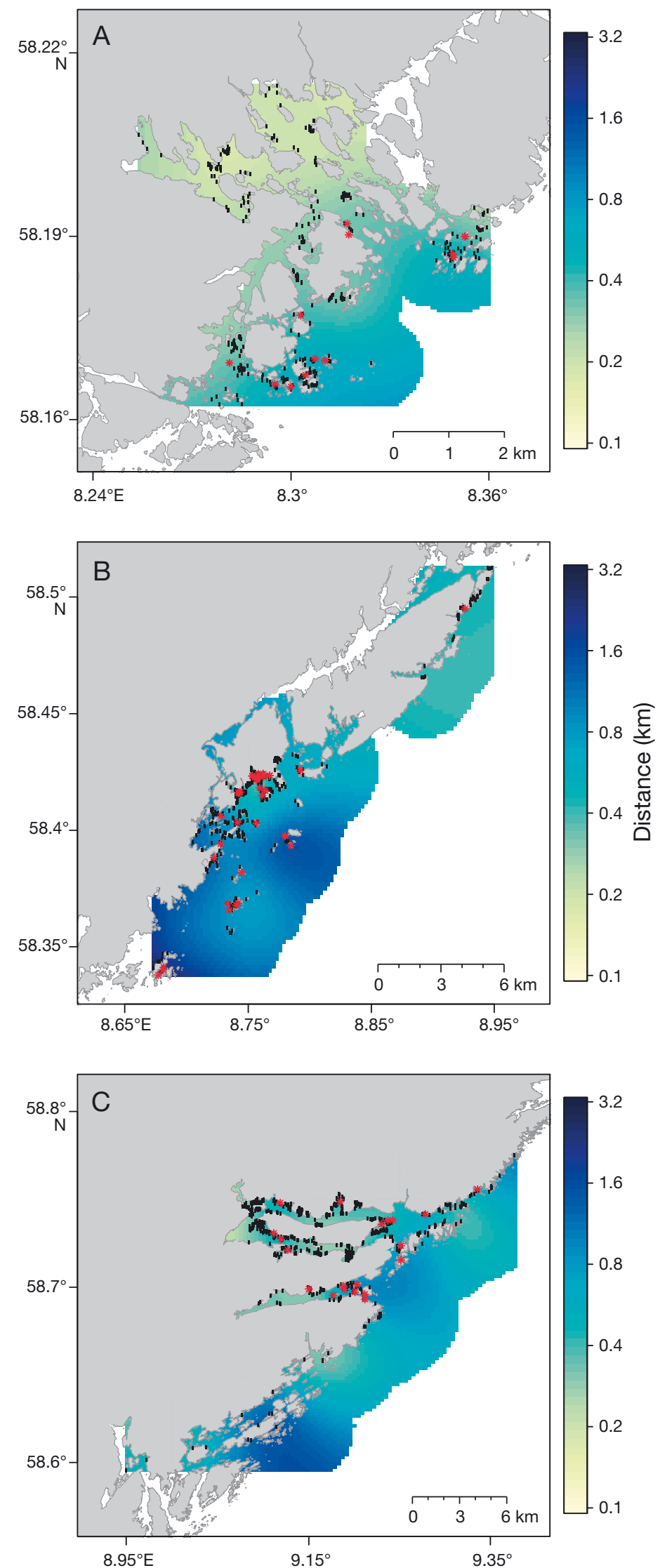
The inclusion of month and days at liberty in the final models suggests temporal patterns in movement. In all regions, movement distance increased with the number of days between tagging and recapture (Fig. S2). However, when only recaptures with at least $1 \mathrm{yr}$ at liberty were included in the model $(\mathrm{n}=$ 89, 243, and 348 for Lillesand, Arendal, and Risør, respectively), time at liberty became insignificant for both Risør and Arendal. In general, the fish recaptured in winter months (Dec to Mar) were recaptured further from where they were tagged than fish recaptured during the rest of the year (Fig. S3 in the Supplement), indicating seasonal changes in behavior or spatio-temporal changes in recapture effort. However, by including the month term in our models we accounted for such variation when estimating the spatial patterns in movement.

\section{DISCUSSION}

The spatial structuring of marine fish populations has long been the subject of scientific investigation and speculation (e.g. Hjort \& Dahl 1900), as it determines at which geographic level local adaptations may evolve, the spatial extent of population impacts caused by local or regional disturbances, and the appropriate spatial scale for management plans. Recent evidence of an erosion of population structure in some marine fishes (Hutchinson 2008), as well as of the importance of maintaining population diversity and local adaptations for fisheries sustainability (Schindler et al. 2010), emphasize the need to correctly characterize population units and the degree of connectivity between those units. With increasing frequency, marine fishes are being described as metapopulations, consisting of several subpopulations mixing to an intermediate degree, rather than larger panmictic units or multiple independent populations (Kritzer \& Sale 2004). Our study indicates that Skagerrak coastal cod fall in the continuum between a metapopulation and multiple independent populations, and that the degree of connectivity likely differs depending on seascape features. While cod in inner fjord areas appear to consist of independent populations, with local recruitment dynamics and highly site-attached adults, cod in exposed areas of the coast likely have greater connectivity over longer distances due to dispersing early life stages. Thus, we find evidence that the population structure on the coast is complex, and cannot easily be described by any single conceptual model of population spatial structure.
Based on the analysis of recruitment time series, the spatial scale of recruitment synchrony clearly differed between exposed (i.e. open) and sheltered regions of the coast, with exposed areas showing elevated correlations in recruitment up to a distance of $\sim 75 \mathrm{~km}$ (Fig. 3). This matches our prediction of higher rates of egg and larval dispersal among open areas, which would act to homogenize the recruitment dynamics along the coastline. Strong coastal currents along the Skagerrak coast in spring may, on average, transport early life stages along the entire coast over ca. 1 wk (cf. Danielssen et al. 1997). In contrast, when comparing among sheltered areas, correlations in recruitment decreased rapidly with distance, remaining above background levels essentially only for stations sampled within a single fjord. An analysis of egg buoyancy and circulation patterns within fjords found that eggs are concentrated in inward-flowing currents, acting as a retention mechanism for eggs spawned locally within fjords (Ciannelli et al. 2010). Tagging studies on recently settled age- 0 cod also indicate that this early life stage is very stationary (Grant \& Brown 1998, Olsen et al. 2004). Our recruitment analysis provides further support for the hypothesis that dispersal among the inner fjord areas is low, and that local spawning populations are largely self-recruiting.

Spatial correlation in recruitment can also be caused by spatial correlation in factors which affect recruitment (Myers et al. 1997), such as zooplankton quality or quantity (Beaugrand et al. 2003). Because average correlations were above zero for all distances, even up to $\sim 280 \mathrm{~km}$, this suggests some common environmental influence on recruitment all along the Skagerrak coast, including exposed and sheltered areas. Indeed, Fromentin et al. (1998) found a low-frequency signal in recruitment that was common to all regions, and not spatially-structured, suggesting a common extrinsic factor such as climate (i.e. a Moran effect; Moran 1953). However, when the long-term trend was removed from our data by first-differencing, and year-to-year variation compared, the spatial patterns remained the same. This demonstrates that similarity in long-term trends is not driving the distance-decay patterns we observed. Environmental conditions could still play a role if conditions are more homogeneous along the outer coast than among fjords, which could result in the different distancedecay patterns found. The higher correlations among nearby areas (within single fjords, and across exposed regions) thus likely contain a signal of both locally correlated environmental conditions and the dispersal of eggs and larvae. Fully quantifying the rela- 
tive contributions of shared environmental conditions and dispersal to the correlation patterns found will require substantial advances in particle-tracking methods or genetic tools such as parentage analysis. However, both indicate important differences in the spatial scale of factors influencing populations in sheltered versus exposed regions.

While both genetics and recruitment data suggest differences in early life-stage dispersal among exposed and sheltered parts of the coastline, the tagging experiment did not show corresponding strong differences in the scales of movement at older life stages. Although cod in the more exposed parts of the coastline were, on average, recaptured slightly further from their point of tagging than cod in the most sheltered fjords, the differences were slight in ecological terms. This raises questions about the ultimate fate and behavior of individuals dispersed as eggs or larvae. In other cod populations, such as the Northeast Arctic cod, long-distance dispersal of larvae is matched by migrations of older age classes back to natal spawning grounds (Robichaud \& Rose 2004). We did not find evidence for consistent natal migrations, either to offshore spawning grounds (e.g. in the North Sea), or along-shore to other coastal spawning grounds. This indicates that any cod of non-local origin are either small in number relative to locally-spawned individuals, or do not demonstrate natal homing behavior and rather carry out their life cycle close to where they settle as juveniles. Only a few immigrants per generation is sufficient to prevent differentiation at neutral genetic markers; thus connectivity among the coastal areas and with offshore stocks may still be very low despite the lack of a clear genetic signal. Determining the fate of early life stage dispersers remains the biggest challenge for characterizing cod population spatial structure in exposed coastal areas.

The limited spatial movements of Skagerrak coastal cod documented herein are remarkable among cod populations. During all months of the year, cod were recaptured, on average, within $2 \mathrm{~km}$ of where they were tagged. Acoustic telemetry studies in the same area found cod home ranges of less than 80 ha, confirming that Skagerrak coastal cod exhibit extraordinary sedentary behavior (Espeland et al. 2007, Olsen et al. 2012). In other cod stocks classified as sedentary, typical movement distances are an order of magnitude longer (10 to $20 \mathrm{~km}$ ) (Robichaud \& Rose 2004), which is still a strong contrast to the $>1000 \mathrm{~km}$ migrations made by Northeast Arctic cod to their spawning grounds each winter. Such remarkable variation in movement illustrates the ability of cod to utilize different physical and behavioral mechanisms to maintain population persistence, and is also likely linked to the spatial scale of population structuring. The extreme sedentary behavior observed in the coastal Skagerrak suggests that cod in this region, particularly in sheltered fjord areas, may exhibit population spatial structure at a finer scale than elsewhere in its range.

While long-distance movements were rare, a small proportion $(\sim 2 \%)$ of individuals were detected to have moved over $20 \mathrm{~km}$. These few long-distance dispersers are indicative of population heterogeneity, and could either be individuals of non-local origin or local cod exhibiting a divergent 'straying' type of behavior. Such divergent movements are common in natural populations of mobile organisms and may represent bold individuals that risk movement across potentially hazardous habitats for potential fitness advantages such as increased growth rate (Fraser et al. 2001). On a population level, even rare longdistance dispersal may influence processes such as gene flow, and ultimately be important for metapopulation dynamics by reducing the occurrence of local extinctions.

The prevalence of long-distance movements may be underestimated due to spatial biases in recapture effort and reporting. Recapture effort by researchers was focused within the 3 study areas; total recapture effort therefore may have been lower outside the study areas relative to inside. However, only a minor fraction $(13 \%)$ of the total recaptures were made by researchers, and evidence from other studies suggests that fishing rates by commercial and recreational fishermen were likely to be relatively high elsewhere along the Norwegian Skagerrak coast, as well as offshore in the Skagerrak, Kattegat, and North Sea. Previous tagging studies in the eastern Skagerrak and Kattegat have reported recapture and reporting rates by commercial fishers ranging from 20 to $66 \%$ depending on region and year (Robichaud \& Rose 2004, Svedäng et al. 2007). There is no reason to believe that reporting rates for the current study should have been lower. Therefore, the very low number of reported recaptures in the Eastern Skagerrak, Kattegat, and North Sea (Table 1, Fig. 4) indicates that migrations of coastal cod to these regions must be rare. Spatial variation in recapture effort could also bias the comparison of sheltered versus protected areas. For instance, if no recapture effort occurred in sheltered regions, only the fish moving out of these areas would be detected. While we cannot quantify the effort, the spatial distribution of recapture locations (Fig. 2) suggests that recapture effort was well distributed throughout the 3 regions. 
Further knowledge of connectivity processes in marine fishes and how they are shaped by seascape features will help to guide conservation and management of marine resources, a highly relevant topic today given the growing human impacts on coastal ecosystems. Marine reserves are increasingly being implemented to aid in the conservation and recovery of exploited populations; however, the effectiveness of marine reserves depends critically on the spatial scale of processes such as larval and adult dispersal (Botsford et al. 2003, Kritzer \& Sale 2004, Grüss et al. 2011). In 2012, Norway's first no-take marine reserve was established in the Tvedestrand fjord between our Arendal and Risør study sites, spanning $1.5 \mathrm{~km}^{2}$ of the inner fjord habitat and including a major cod spawning and nursery area (Ciannelli et al. 2010). Marine reserves are generally not considered for highly migratory species such as Atlantic cod, but what we now know about movement and dispersal of Skagerrak coastal cod suggests that even a relatively small reserve could be an effective conservation tool in this region, protecting sedentary adults from harvest (see also Moland et al. 2013). However, any spill-over benefits to fishers outside the reserve will depend on relative dispersal rates of eggs and larvae into and out of the reserve (Botsford et al. 2003), which likely vary among inshore versus exposed areas. Reserve placement within the coastal seascape will therefore be critical for its success, depending on the stated (conservation and/or fisheries) goals.

Identifying the spatial scale of population structuring is critical for the successful monitoring, management, and conservation of marine fishes. Current fisheries management strategies are often criticized for not considering population units at an appropriate biological scale (Hutchinson 2008, Reiss et al. 2009). Our results emphasize how the processes underlying spatial population structuring can differ across space, as well as through a life-cycle, resulting in a complex spatial population structure mapped on a heterogeneous seascape. Such spatial complexity is certainly not unique to this system, and calls for the development of management strategies that are either adapted to, or robust to uncertainties in population spatial structure.

Acknowledgements. We thank colleagues at IMR Flødevigan for valuable assistance in data collection and management. The preparation of this paper has been supported by The Research Council of Norway (projects CODFLICT, CROSCON, and PROMAR) and by the Norden Top-level Research Initiative sub-program 'Effect Studies and Adaptation to Climate Change' through the Nordic Centre for Research on Marine Ecosystems and Resources under Climate Change (NorMER).

\section{LITERATURE CITED}

Baguette M, Van Dyke H (2007) Landscape connectivity and animal behavior: functional grain as a key determinant for dispersal. Landscape Ecol 22:1117-1129

Banks SC, Piggott MP, Williamson JE, Bove U, Holbrook NJ, Beheregaray LB (2007) Oceanic variability and coastal topography shape genetic structure in a long-dispersing sea urchin. Ecology 88:3055-3064

> Beaugrand G, Brander KM, Lindley JA, Souissi S, Reid PC (2003) Plankton effect on cod recruitment in the North Sea. Nature 426:661-664

Bjørnstad ON, Ims R, Lambin X (1999) Spatial population dynamics: analyzing patterns and processes of population synchrony. Trends Ecol Evol 14:427-432

Botsford LW, Micheli F, Hastings A (2003) Principles for the design of marine reserves. Ecol Appl 13(Suppl):25-31

Brattey J, Cadigan N (2004) Estimation of short-term tagging mortality of adult Atlantic cod (Gadus morhua). Fish Res 66:223-233

Cadigan N, Brattey J (2006) Reporting and shedding rate estimates from tag-recovery experiments on Atlantic cod (Gadus morhua) in coastal Newfoundland. Can J Fish Aquat Sci 63:1944-1958

Ciannelli L, Knutsen H, Olsen EM, Espeland SH and others (2010) Small-scale genetic structure in a marine population in relation to water circulation and egg characteristics. Ecology 91:2918-2930

Ciannelli L, Fisher J, Skern-Mauritzen M, Hunsicker ME, Hidalgo M, Frank KT, Bailey KM (2013) Theory, consequences and evidence of eroding population spatial structure in harvested marine fishes: a review. Mar Ecol Prog Ser 480:227-243

Conover DO, Clarke LM, Munch SB, Wagner GN (2006) Spatial and temporal scales of adaptive divergence in marine fishes and the implications for conservation. J Fish Biol 69:21-47

> Danielssen DS, Edler L, Fonselius S, Hernroth L, Ostrowski M, Svendsen E, Talpsepp L (1997) Oceanographic variability in the Skagerrak and Northern Kattegat, MayJune, 1990. ICES J Mar Sci 54:753-773

Dannevig A (1954) The littoral cod of the Norwegian Skagerak coast. Rapp P-V Reùn Cons Int Explor Mer 136: $7-14$

> Engen S, Saether BE, Sverdrup-Thygeson A, Grøtan V, Ødegaard F (2008) Assessment of species diversity from species abundance distributions at different localities. Oikos 117:738-748

Espeland $\mathrm{SH}$, Gundersen AF, Olsen EM, Knutsen $\mathrm{H}$, Gjøsæter J, Stenseth NC (2007) Home range and elevated egg densities within an inshore spawning ground of coastal cod. ICES J Mar Sci 64:920-928

> Fraser DF, Gilliam JF, Daley MJ, Le AN, Skalski GT (2001) Explaining leptokurtic movement distributions: intrapopulation variation in boldness and exploration. Am Nat 158:124-135

Frisk MG, Jordaan A, Miller TJ (2014) Moving beyond the current paradigm in marine population connectivity: are adults the missing link? Fish Fish 15:242-254

Fromentin JM, Stenseth NC, Gjøsæter J, Johannessen T, Planque B (1998) Long-term fluctuations in cod and pollack along the Norwegian Skagerrak coast. Mar Ecol Prog Ser 162:265-278

Grant SM, Brown JA (1998) Nearshore settlement and localized populations of age 0 Atlantic cod (Gadus morhua) in 
shallow coastal waters of Newfoundland. Can J Fish Aquat Sci 55:1317-1327

- Grüss A, Kaplan DM, Hart DR (2011) Relative impacts of adult movement, larval dispersal and harvester movement on the effectiveness of reserve networks. PLoS ONE 6:e19960

> Hastings A (1993) Complex interactions between dispersal and dynamics: lessons from coupled logistic equations. Ecology 74:1362-1372

> Hauser L, Carvalho GR (2008) Paradigm shifts in marine fisheries genetics: ugly hypotheses slain by beautiful facts. Fish Fish 9:333-362

Hjort J, Dahl K (1900) Fishing experiments in Norwegian fiords. Rep Norweg Fish Mar Invest 1:1-214

> Hutchings JA, Swain DP, Rowe S, Eddington JD, Puvanendran V, Brown JA (2007) Genetic variation in life-history reaction norms in a marine fish. Proc Biol Sci 274: 1693-1699

Hutchinson WF (2008) The dangers of ignoring stock complexity in fishery management: the case of the North Sea cod. Biol Lett 4:693-695

> Jones GP, Milicich MJ, Emslie MJ, Lunow C (1999) Selfrecruitment in a coral reef fish population. Nature 402: 802-804

> Jorde PE, Knutsen H, Espeland SH, Stenseth NC (2007) Spatial scale of genetic structuring in coastal cod Gadus morhua and geographic extent of local populations. Mar Ecol Prog Ser 343:229-237

Julliard R, Stenseth NC, Gjøsæter J, Lekve K, Fromentin JM, Danielssen DS (2001) Natural mortality and fishing mortality in a coastal cod population: a release-recapture experiment. Ecol Appl 11:540-558

- Kjesbu O (1989) The spawning activity of cod, Gadus morhua L. J Fish Biol 34:195-206

Knutsen H, Jorde PE, André C, Stenseth NC (2003) Finescaled geographical population structuring in a highly mobile marine species: the Atlantic cod. Mol Ecol 12: 385-394

Knutsen H, André C, Jorde PE, Skogen MD, Thuróczy E, Stenseth NC (2004) Transport of North Sea cod larvae into the Skagerrak coastal populations. Proc Biol Sci 271: 1337-1344

Knutsen JA, Knutsen H, Rinde E, Christie H, Bodvin T, Dahl E (2010) Mapping biological resources in the coastal zone: an evaluation of methods in a pioneering study from Norway. Ambio 39:148-158

Knutsen H, Olsen EM, Jorde PE, Espeland SH, André C, Stenseth NC (2011) Are low but statistically significant levels of genetic differentiation in marine fishes 'biologically meaningful?' A case study of coastal Atlantic cod. Mol Ecol 20:768-783

Koehn RK, Newell RI, Immermann F (1980) Maintenance of an aminopeptidase allele frequency cline by natural selection. Proc Natl Acad Sci USA 77:5385-5389

Kritzer JP, Sale PF (2004) Metapopulation ecology in the sea: from Levins' model to marine ecology and fisheries science. Fish Fish 5:131-140

Manel S, Schwartz MK, Luikart G, Taberlet P (2003) Landscape genetics: combining landscape ecology and popu-

Editorial responsibility: Edward Durbin, Narragansett, Rhode Island, USA lation genetics. Trends Ecol Evol 18:189-197

Moland E, Olsen EM, Knutsen H, Garrigou P and others (2013) Lobster and cod benefit from small scale northern marine protected areas: inference from an empirical before-after control-impact study. Proc R Soc Lond B Biol Sci 280:20122679

Moran P (1953) The statistical analysis of the Canadian lynx cycle. Aust J Zool 1:291-298

> Morgan SG, Fisher JL, Miller SH, McAfee ST, Largier JL (2009) Nearshore larval retention in a region of strong upwelling and recruitment limitation. Ecology 90:34893502

Myers RA, Mertz G, Bridson J (1997) Spatial scales of interannual recruitment variations of marine, anadromous, and freshwater fish. Can J Fish Aquat Sci 54:1400-1407

O'Hara RB, Kotze DJ (2010) Do not log-transform count data. Method Ecol Evol 1:118-122

> Olsen EM, Gjøsæter J, Stenseth NC (2004) Evaluation of the use of visible implant tags in age-0 Atlantic cod. N Am J Fish Manage 24:282-286

Olsen EM, Knutsen H, Gjøsæter J, Jorde PE, Knutsen JA, Stenseth NC (2008) Small-scale biocomplexity in coastal Atlantic cod supporting a Darwinian perspective on fisheries management. Evol Appl 1:524-533

Olsen EM, Heupel MR, Simpfendorfer CA, Moland E (2012) Harvest selection on Atlantic cod behavioral traits: implications for spatial management. Ecol Evol 2:1549-1562

R Development Core Team (2011) R: a language and environment for statistical computing. R Foundation for Statistical Computing, Vienna

Reiss H, Hoarau G, Dickey-Collas M, Wolff WJ (2009) Genetic population structure of marine fish: mismatch between biological and fisheries management units. Fish Fish 10:361-395

Robichaud D, Rose GA (2004) Migratory behaviour and range in Atlantic cod: inference from a century of tagging. Fish Fish 5:185-214

Schindler DE, Hilborn R, Chasco B, Boatright CP, Quinn TP, Rogers LA, Webster MS (2010) Population diversity and the portfolio effect in an exploited species. Nature 465: 609-612

Sponaugle S, Cowen RK, Shanks A, Morgan SG and others (2002) Predicting self-recruitment in marine populations: biophysical correlates and mechanisms. Bull Mar Sci 70 : 341-375

> Stenseth NC, Bjørnstad ON, Falck W, Fromentin JM, Gjøsæter J, Gray J (1999) Dynamics of coastal cod populations: intra- and intercohort density dependence and stochastic processes. Proc R Soc Lond B Biol Sci 266: 1645-1654

> Svedäng H, Righton DA, Jonsson P (2007) Migratory behaviour of Atlantic cod Gadus morhua: natal homing is the prime stock-separating mechanism. Mar Ecol Prog Ser 345:1-12

> Thorrold SR, Latkoczy C, Swart PK, Jones CM (2001) Natal homing in a marine fish metapopulation. Science 291: 297-299

Wood SN (2006) Generalized additive models: an introduction with R. CRC Press, Boca Raton, FL

Submitted: January 22, 2014; Accepted: July 11, 2014

Proofs received from author(s): September 15, 2014 